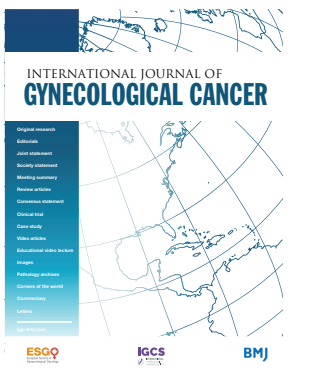

- Additional supplemental material is published online only. To view, please visit the journal online (http://dx.doi.org/ 10.1136/ijgc-2021-002601).

For numbered affiliations see end of article.

Correspondence to Dr Surbhi Grover, Radiation Oncology, University of Pennsylvania, Philadelphia, PA 19104, USA; surbhi.grover@ pennmedicine.upenn.edu

Received 9 March 2021 Accepted 8 July 2021 Published Online First 26 July 2021

\section{Check for updates}

(C) IGCS and ESGO 2021. No commercial re-use. See rights and permissions. Published by BMJ.

To cite: Grover S, Ning MS, Bale M, et al. Int J Gynecol

Cancer 2021;31:1220-1227.

\title{
Chemoradiation versus radiation alone in stage IIIB cervical cancer patients with or without human immunodeficiency virus
}

Surbhi Grover, ${ }^{1,2}$ Matthew S Ning, ${ }^{3}$ Michelle Bale, ${ }^{4}$ Katie E Lichter, ${ }^{5}$ Sidrah Shah, ${ }^{6}$ Memory Bvochora-Nsingo, ${ }^{7}$ Sebathu Chiyapo, ${ }^{7}$ Dawn Balang, ${ }^{7}$ Gwendolyn J McGinnis, ${ }^{8}$ Tlotlo Ralefala, ${ }^{9}$ Thabo Moloi, ${ }^{9}$ Rebecca Luckett, ${ }^{10}$ Doreen Ramogola-Masire, ${ }^{11}$ Erle S Robertson, ${ }^{12}$ Nicola M Zetola ${ }^{13}$

\section{HIGHLIGHTS}

- Chemoradiation is associated with improved survival in patients with International Federation of Gynecology and Obstetrics (FIGO) 2009 stage IIIB cervical cancer compared with radiation alone.

- Addition of chemotherapy improved survival regardless of HIV status.

- Chemotherapy is especially vital when full dose radiation is not received.

\section{ABSTRACT}

Objective Cervical cancer remains the most common cancer among women in sub-Saharan Africa and is also a leading cause of cancer related deaths among these women. The benefit of chemoradiation in comparison with radiation alone for patients with stage IIIB disease has not been evaluated prospectively in women living with human immunodeficiency virus (HIV). We assessed the survival of chemoradiation versus radiation alone among stage IIIB cervical cancer patients based on HIV status.

Methods Between February 2013 and June 2018, patients with International Federation of Gynecology and Obstetrics (FIG0) 2009 stage IIIB cervical cancer with or without HIV and treated with chemoradiation or radiation alone, were prospectively enrolled in an observational cohort study. Overall survival was evaluated using the Kaplan-Meier method. Cox proportional hazards modeling was used to analyze associations with survival. Results Among 187 patients, $63 \%(n=118)$ of women had co-infection with HIV, and $48 \%(n=69)$ received chemoradiation. Regardless of HIV status, patients who received chemoradiation had improved 2 year overall survival compared with those receiving radiation alone ( $59 \%$ vs $41 \%, p<0.01$ ), even among women living with HIV (60\% vs $38 \%, p=0.02$ ). On multivariable Cox regression analysis, including all patients regardless of HIV status, 2 year overall survival was associated with receipt of chemoradiation (hazard ratio $(\mathrm{HR}) 0.63, \mathrm{p}=0.04$ ) and total radiation dose $\geq 80$ Gy (HR $0.57, p=0.02$ ). Among patients who received an adequate radiation dose of $\geq 80$ Gy, adjusted overall survival rates were similar between chemoradiation versus radiation alone groups (HR 1.07; $p=0.90$ ). However, patients who received an inadequate radiation dose of $<80 \mathrm{~Gy}$, adjusted survival was significantly higher in chemoradiation versus radiation alone group (HR 0.45, $p=0.01$ ).

Conclusions Addition of chemotherapy to standard radiation improved overall survival, regardless of HIV status, and is even more essential in women who cannot receive full doses of radiation.

\section{INTRODUCTION}

Cervical cancer is a leading cause of cancer death among women in low and middle income countries worldwide, many of which are in sub-Saharan Africa. ${ }^{1}$ High rates of cervical cancer in this region are closely linked to endemic human immunodeficiency virus (HIV) infection, with women living with HIV having a 4-5-fold increased likelihood of developing cervical cancer. $^{2}{ }^{3}$ This is likely due to higher persistence of human papillomavirus (HPV) infection, ${ }^{2}{ }^{4}$ which is known to be associated with almost all cervical cancer, in patients with HIV compared with patients without HIV, and limited access to cervical cancer screening programs in sub-Saharan Africa. ${ }^{5}$ Furthermore, patients with HIV are living longer because antiretroviral therapy is providing a greater opportunity for cervical cancer to develop due to HPV persistence. The higher rates of HPV associated cancers among persons living with HIV further support these theories. ${ }^{4}$ This link between HIV and cervical cancer is especially apparent in Botswana, where the rate of HIV infection among women aged $15-49$ is $24.6 \%$, and two-thirds of cervical cancer cases occur in women living with IIV. $^{67}$

Chemoradiation has been the standard of care for locally advanced cervical cancer ${ }^{7}$ since the publication of five phase III clinical trials showing a $30-50 \%$ increase in cervical cancer survival rates compared with radiation alone. ${ }^{8-12}$ However, data regarding its benefit over radiation in patients with stage IIIB disease have been mixed. A meta-analysis of 13 randomized controlled trials comparing chemoradiation with radiation alone in the treatment of cervical cancer found a survival benefit of only $3 \%$ in advanced stages (III-IVA), compared with a $10 \%$ survival benefit seen in early stages $(\mathrm{IB}-\mathrm{II} A) \cdot{ }^{13} \mathrm{~A}$ subsequent randomized controlled trial from Brazil of patients with stage IIIB cervical 
Table 1 Baseline demographic and treatment

characteristics by HIV status of women with FIGO 2009 stage IIIB cervical cancer in Botswana

\begin{tabular}{|c|c|c|c|}
\hline Characteristic & $\begin{array}{l}\text { HIV } \\
\text { seropositive } \\
\text { (n=118 (63.1\%)) }\end{array}$ & $\begin{array}{l}\text { HIV } \\
\text { seronegative } \\
(n=69(36.9 \%))\end{array}$ & $P$ value \\
\hline \multicolumn{4}{|l|}{ Age (years) } \\
\hline Median (IQR) & $46(39-50)$ & $61(49-70)$ & $<0.01$ \\
\hline \multicolumn{4}{|l|}{ Weight $(\mathrm{kg})^{\star}$} \\
\hline$<60$ & $42(42)$ & $32(57)$ & 0.08 \\
\hline$\geq 60$ & $57(58)$ & $24(43)$ & \\
\hline \multicolumn{4}{|c|}{$\begin{array}{l}\text { Median (IQR) } 59 \\
(50-75)\end{array}$} \\
\hline \multicolumn{4}{|c|}{$\begin{array}{l}\text { Body mass index }(\mathrm{kg} / \\
\left.\mathrm{m}^{2}\right)^{*}\end{array}$} \\
\hline$\leq 20$ & $31(34)$ & $11(22)$ & 0.13 \\
\hline$>20$ & $61(66)$ & $40(78)$ & \\
\hline \multicolumn{4}{|c|}{$\begin{array}{l}\text { Median (IQR) } 23 \\
(19-28)\end{array}$} \\
\hline \multicolumn{4}{|l|}{ Tumor histology } \\
\hline ScC & $102(86)$ & $63(91)$ & 0.32 \\
\hline Non-SCC & $16(14)$ & $6(9)$ & \\
\hline \multicolumn{4}{|c|}{ History of tuberculosis } \\
\hline Yes & $15(13)$ & $2(3)$ & 0.02 \\
\hline No & $103(87)$ & $67(97)$ & \\
\hline \multicolumn{4}{|c|}{ CD4 count (cells $/ \mathrm{mL})^{*}$} \\
\hline$<400$ & $62(56)$ & $\mathrm{N} / \mathrm{A}$ & $\mathrm{N} / \mathrm{A}$ \\
\hline$\geq 400$ & $49(44)$ & & \\
\hline \multicolumn{4}{|c|}{$\begin{array}{l}\text { Median (IQR) } 445 \\
(319-657)\end{array}$} \\
\hline \multicolumn{4}{|c|}{ Viral load (cells $/ \mathrm{mL})^{*}$} \\
\hline$\geq 400$ & $11(13)$ & $\mathrm{N} / \mathrm{A}$ & $\mathrm{N} / \mathrm{A}$ \\
\hline$<400$ & $75(87)$ & & \\
\hline \multicolumn{4}{|c|}{ Hemoglobin $(g / d L)^{*}$} \\
\hline$<12$ & $93(86)$ & $46(72)$ & 0.02 \\
\hline$\geq 12$ & $15(14)$ & $18(28)$ & \\
\hline \multicolumn{4}{|c|}{$\begin{array}{l}\text { Median (IQR) } 10.2 \\
(8.7-11.5)\end{array}$} \\
\hline \multicolumn{4}{|c|}{ Creatinine $(\mu \mathrm{mol} / \mathrm{L})^{\star}$} \\
\hline$>90$ & $15(13)$ & $16(25)$ & 0.05 \\
\hline$\leq 90$ & $99(87)$ & $49(75)$ & \\
\hline \multicolumn{4}{|c|}{$\begin{array}{l}\text { Median (IQR) } 65 \\
(51-84)\end{array}$} \\
\hline \multicolumn{4}{|l|}{$\mathrm{KPS}^{*}$} \\
\hline $40-80$ & $32(27)$ & $22(32)$ & 0.51 \\
\hline $90-100$ & $85(73)$ & $47(68)$ & \\
\hline \multicolumn{4}{|c|}{$\begin{array}{l}\text { Median (IQR) } 90 \\
(40-100)\end{array}$} \\
\hline \multicolumn{4}{|l|}{ ART } \\
\hline Yes & $110(93)$ & $N / A$ & $\mathrm{~N} / \mathrm{A}$ \\
\hline No & $8(7)$ & & \\
\hline \multicolumn{4}{|l|}{ Treatment year } \\
\hline 2013-2015 & $42(36)$ & $31(45)$ & 0.21 \\
\hline 2016-2018 & $76(64)$ & $38(55)$ & \\
\hline
\end{tabular}

Continued
Table 1 Continued

\begin{tabular}{|c|c|c|c|}
\hline Characteristic & $\begin{array}{l}\text { HIV } \\
\text { seropositive } \\
(n=118(63.1 \%))\end{array}$ & $\begin{array}{l}\text { HIV } \\
\text { seronegative } \\
(n=69(36.9 \%))\end{array}$ & $P$ value \\
\hline \multicolumn{4}{|l|}{ TT*† (months) } \\
\hline$>3$ months & $58(60)$ & $32(68)$ & 0.37 \\
\hline$\leq 3$ months & $38(40)$ & $15(32)$ & \\
\hline \multicolumn{4}{|l|}{$\begin{array}{l}\text { Median (IQR) } 3.4 \\
(2.3-5.0)\end{array}$} \\
\hline \multicolumn{4}{|c|}{$\begin{array}{l}\text { Total RT dose, EQD2 } \\
\text { (Gy) }\end{array}$} \\
\hline$\geq 80$ & $43(36)$ & $22(32)$ & 0.528 \\
\hline$<80$ & $75(64)$ & $47(68)$ & \\
\hline \multicolumn{4}{|l|}{$\begin{array}{l}\text { Median (IQR) } 68 \\
(55-74)\end{array}$} \\
\hline \multicolumn{4}{|l|}{$\begin{array}{l}\text { RT course length* } \\
\text { (weeks) }\end{array}$} \\
\hline$<7$ & $64(54)$ & $42(62)$ & 0.318 \\
\hline$\geq 7$ & $54(46)$ & $26(38)$ & \\
\hline \multicolumn{4}{|l|}{$\begin{array}{l}\text { Median (IQR) } 47 \\
\text { days (39-52) }\end{array}$} \\
\hline \multicolumn{4}{|l|}{ Brachytherapy } \\
\hline Yes & $78(66)$ & $42(61)$ & 0.47 \\
\hline No & $40(34)$ & 27 (39) & \\
\hline \multicolumn{4}{|l|}{ EBRT boost } \\
\hline Yes & $37(31)$ & $21(30)$ & 0.90 \\
\hline No & $81(69)$ & $48(70)$ & \\
\hline \multicolumn{4}{|l|}{ CRT } \\
\hline Yes & $58(49)$ & $32(46)$ & 0.71 \\
\hline No & $60(51)$ & $37(54)$ & \\
\hline \multicolumn{4}{|c|}{ Treatment response ${ }^{\star} \ddagger$} \\
\hline Complete & $49(48)$ & $31(57)$ & 0.24 \\
\hline Non-complete & $54(52)$ & $23(43)$ & \\
\hline
\end{tabular}

*Data are incomplete due to missing individual patient data.

†TTT is defined as time from pathological diagnosis to initiation of treatment. $\ddagger$ Treatment response is defined as clinically apparent tumor regression on examination.

ART, antiretroviral therapy; BMI, body mass index; CRT, chemoradiation therapy; EBRT, external beam radiation therapy; EQD2, radiobiological equivalent dose; FIGO, International Federation of Gynecology and Obstetrics; HIV, human immunodeficiency virus; KPS, Karnofsky Performance Score; RT, radiation therapy; SCC, squamous cell carcinoma.;

cancer showed that although chemoradiation improved disease free survival, overall survival was not significantly impacted. ${ }^{14}$ Most recently, however, a randomized control trial from India of patients with stage IIIB disease found that chemoradiation provided significant benefit in both disease free survival and overall survival compared with radiation alone. ${ }^{15}$ However, women living with HIV were excluded from this study. The addition of chemotherapy to standard radiation warrants closer study in women living with HIV given their disproportionate representation among patients with cervical cancer in low and middle income countries, particularly in sub-Saharan Africa. ${ }^{16}$ Chemotherapy is not only an additional cost for patients, ${ }^{17}$ but also significantly increases rates of grade III/IV hematologic toxicities. ${ }^{18}$ It is therefore important to understand the effects of resource intensive standard treatment recommendations, 


\section{Original research}

such as chemoradiation in this specific population, namely women living with HIV in resource limited settings. ${ }^{19}$

The benefit of chemoradiation versus radiation remains unknown in women living with HIV. To this end, we prospectively assessed outcomes among stage IIIB cervical cancer to evaluate the survival benefit of chemoradiation versus radiation alone, in all patients regardless of viral status, and among women living with and without HIV in Botswana.

\section{METHODS}

\section{Study Site and Population}

All consecutive patients with International Federation of Gynecology and Obstetrics (FIGO) 2009 stage IIIB cervical cancer, with or without HIV, who presented for chemoradiation or radiation between February 2013 and June 2018 were enrolled in the Botswana Prospective Cancer Cohort, a prospective cohort study of patients receiving cancer treatment in Botswana. Patients were seen at the Gynecologic Multi-Disciplinary Team clinic at Princess Marina Hospital, a tertiary public hospital, and received treatment at the Gaborone Private Hospital, the only radiation oncology facility in the country. Botswana has a publicly funded healthcare system for its citizens, and all the costs associated with cancer treatment, including radiation at Gaborone Private Hospital, are covered by the government. The Gynecologic Multi-Disciplinary Team clinic, established in 2016, specializes in the diagnosis, treatment planning, and follow-up of patients with gynecologic cancers. ${ }^{20} \mathrm{~A}$ radiation oncologist, medical oncologist, gynecologist, pathologist, palliative care

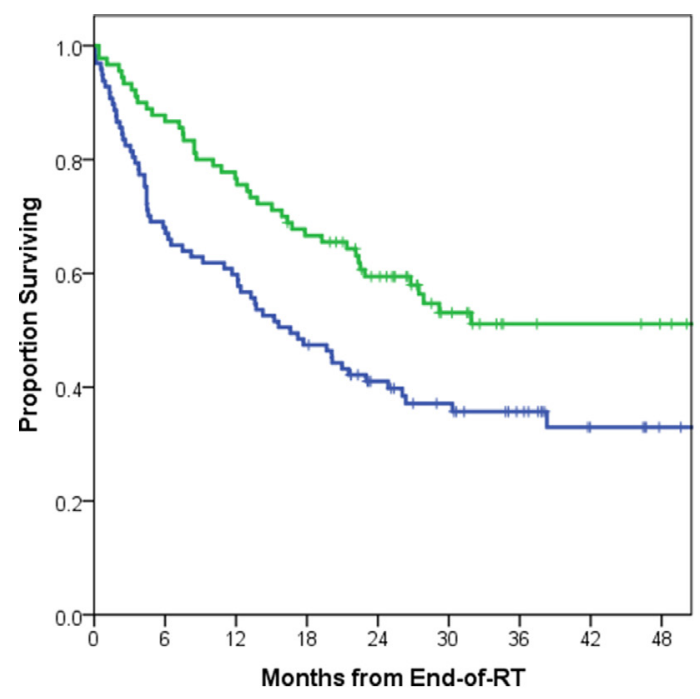

Treatment $\neg$ RT (n=97) $\rightarrow$ CRT $(n=90$ + censored

\begin{tabular}{|l|l|l|l|l|l|l|l|l|l|}
\hline $\begin{array}{l}\text { Chemo } \\
\text { radiatio }\end{array}$ & 90 & 66 & 58 & 46 & 33 & 26 & 19 & 10 & 6 \\
\hline $\begin{array}{l}\text { Radiati } \\
\text { on } \\
\text { Alone }\end{array}$ & 97 & 79 & 69 & 59 & 47 & 30 & 21 & 20 & 18 \\
\hline
\end{tabular}

Figure 1 Survival outcomes by receipt of chemotherapy for all International Federation of Gynecology and Obstetrics (FIGO) 2009 stage IIIB cervical cancer patients in Botswana: chemoradiation therapy (CRT) $(n=90)$ versus radiation therapy $(R T)$ alone $(n=97)$. specialist, and nurse coordinator work together to provide streamlined multidisciplinary care for patients.

\section{Data Collection}

Data were collected via predesigned electronic forms and database management tools (Research Electronic Data Capture (REDCap), hosted at the University of Pennsylvania). At initial patient visits, the following data were collected through patient interviews and medical records: demographics, prior medical history, weight and height, initial presenting symptoms, history of HIV and/or tuberculosis, history of antiretroviral therapy, performance status using the Karnofsky Performance Status score, ${ }^{21}$ relevant baseline laboratory values (hemoglobin $\mathrm{g} / \mathrm{dL}$, creatinine $\mu \mathrm{mol} / \mathrm{L}, \mathrm{CD} 4$ count cells $/ \mathrm{mL}$, viral load cells $/ \mathrm{mL}$ ), time to treatment (defined as the time from the patient's biopsy to the start of treatment), and treatment prescribed. Chemotherapy cycles were documented weekly during treatment visits. The total radiation dose received to point $\mathrm{A}$, calculated using the radiobiological equivalent dose (EQD2) formula, was recorded at the end of radiation therapy treatment. ${ }^{22}$ Following enrollment, patients were followed prospectively until death via clinic visits and/or phone calls.

The institutional review boards of the Ministry of Health of Botswana Princess Marina Hospital and the University of Pennsylvania approved the study. Written consent was obtained from all participants prior to enrollment.

\section{Cervical Cancer Treatment}

Treatment for patients presenting with FIGO 2009 stage IIIB cervical cancer was prescribed following National Comprehensive Cancer Network guidelines, ${ }^{23}$ which recommend chemoradiation for all patients who can tolerate it. Staging and treatment procedures for cervical cancer patients in Botswana have been described previously in our previous publication. ${ }^{5}$ Concurrent cisplatin was the chemotherapy of choice. Decision to treat with chemoradiation versus radiation was made by the treating physician based on various factors, including renal function, performance status, and anemia. High dose rate brachytherapy was recommended for all stage IIIB cervical cancer patients. External beam radiation therapy boost was prescribed when deemed necessary, including in cases of gross disease in the parametria or involved unresected nodes.

\section{Antiretroviral Treatment}

The Botswana National antiretroviral therapy program provides eligible citizens with antiretroviral therapy at no personal cost. When the study was initiated in 2013, patients in Botswana were only eligible for antiretroviral therapy if they had CD4 counts $\leq 350$ cells/ $\mu \mathrm{L}$ or were noted to have stage 3-4 World Health Organization HIV conditions, including cervical cancer. ${ }^{24}$ Patients meeting these criteria were started on efavirenz, tenofovir disoproxil fumarate, and emtricitabine as standard first line antiretroviral therapy. By June of 2016, all persons living with HIV, regardless of CD4 count and/or viral load, were able to start antiretroviral therapy via a Universal Test and Treat Strategy. During this initiative, patients were started on first line dolutegravir-tenofovir disoproxil fumarate and emtricitabine therpay. ${ }^{25}$ In the present study, all patients were tested for HIV as confirmation prior to initiation of cancer treatment. Prior to starting cancer treatment, all women living with HIV were started on antiretroviral therapy, if not already on therapy. 


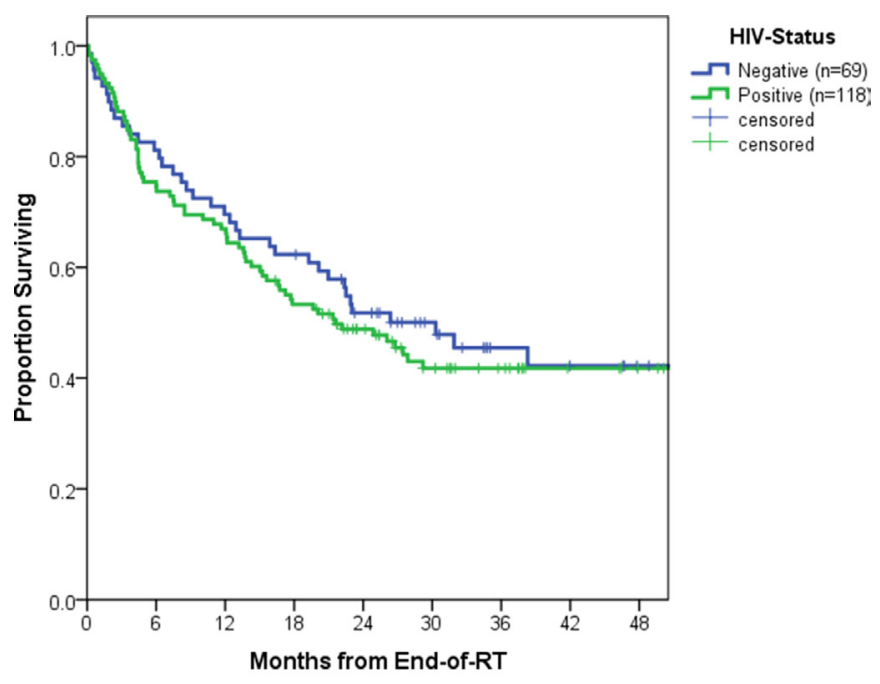

\begin{tabular}{|l|l|l|l|l|l|l|l|l|l|}
\hline $\begin{array}{l}\text { HIV- } \\
\text { positive }\end{array}$ & 118 & 89 & 79 & 62 & 47 & 33 & 26 & 18 & 15 \\
\hline $\begin{array}{l}\text { HIV- } \\
\text { negative }\end{array}$ & 69 & 56 & 48 & 43 & 33 & 23 & 14 & 12 & 9 \\
\hline
\end{tabular}

Figure 2 Survival outcomes by human immunodeficiency virus status for patients with International Federation of Gynecology and Obstetrics (FIGO) 2009 IIIB cervical cancer in Botswana. $\mathrm{RT}$, radiation therapy.

\section{Primary Outcome}

The primary endpoint of the study was 2 year overall survival among all women treated with chemoradiation versus radiation alone, in women living with HIV treated with chemoradiation versus radiation alone, and in women living without HIV treated with chemoradiation versus radiation alone. Overall survival was defined as the time from the last radiation received until death or until last contact with the patient. Overall survival was evaluated at 2 years as it has been found that $80 \%$ of recurrences and deaths due to cervical cancer occur in the first 2 years of treatment. ${ }^{3}$ Patients were censored at the last follow-up. If a patient, or their next of kin, was unable to be contacted via telephone, medical records were queried to investigate vital status and/or the date of the patient's last known visit to a healthcare facility. The patient was censored at that date if vital status was not recorded.

\section{Statistical Analysis}

Patient subgroups were divided based on factors including HIV status, treatment type (chemoradiation vs radiation alone), and adequacy of radiation dose (total radiation dose $\geq 80$ Gy or $<80$ Gy). Patient subgroup demographic and clinical characteristics were compared using the Mann-Whitney test for continuous variables and $\chi^{2}$ tests for categorical variables. Actuarial rates of overall survival were analyzed via the Kaplan-Meier method, using log rank tests to compare groups (overall survival among women receiving chemoradiation vs radiation alone and overall survival among women with HIV receiving chemoradiation vs radiation and women without HIV receiving chemoradiation vs radiation alone). Associations of clinical and treatment characteristics with overall survival were calculated via univariate and multivariable Cox proportional hazards modeling, with hazard ratios (HRs) calculated. Analyses were performed using SPSS V.24 (IBM Corp, Armonk, New
York, USA). For all analyses, the threshold for statistical significance was $p<0.05$.

\section{RESULTS}

\section{Patient Demographic and Clinical Characteristics}

Patient, disease, and treatment characteristics of women living with and without HIV infection are compared in Table 1. In total, 187 patients were included and median follow-up time was 22 months (95\% confidence interval (Cl) 8 to 34 months). Median age was 49 years (interquartile range (IQR) 41-60 years). Women living with HIV ( $n=118 / 187,63 \%)$ were younger than women without HIV infection (median 46 vs 61 years, $p<0.01$ ). The median CD4 count among women living with HIV was 445 cells/mL (IQR 319-657 cells $/ \mathrm{mL}$ ) and $75 / 86(87 \%)$ had a viral load $<400$ cells $/ \mathrm{mL}$. Most women $(110 / 118,93 \%)$ were receiving antiretroviral therapy at the time of cervical cancer diagnosis. Baseline creatinine levels were $\leq 90 \mu \mathrm{mol} / \mathrm{L}$ in 99/118 (87\%) women with HIV and in 49/69 (75\%) women without HIV $(p=0.05)$. Of the patients with available baseline hemoglobin values, baseline hemoglobin levels were $<12 \mathrm{~g} /$ dL in 93/108 (86\%) women with HIV versus $46 / 64(72 \%)$ women without HIV ( $p=0.02)$. Histopathology results confirmed that 165 $(88 \%)$ of 187 patients had squamous cell carcinoma whereas $22(12 \%)$ patients had non-squamous cell carcinoma. Baseline

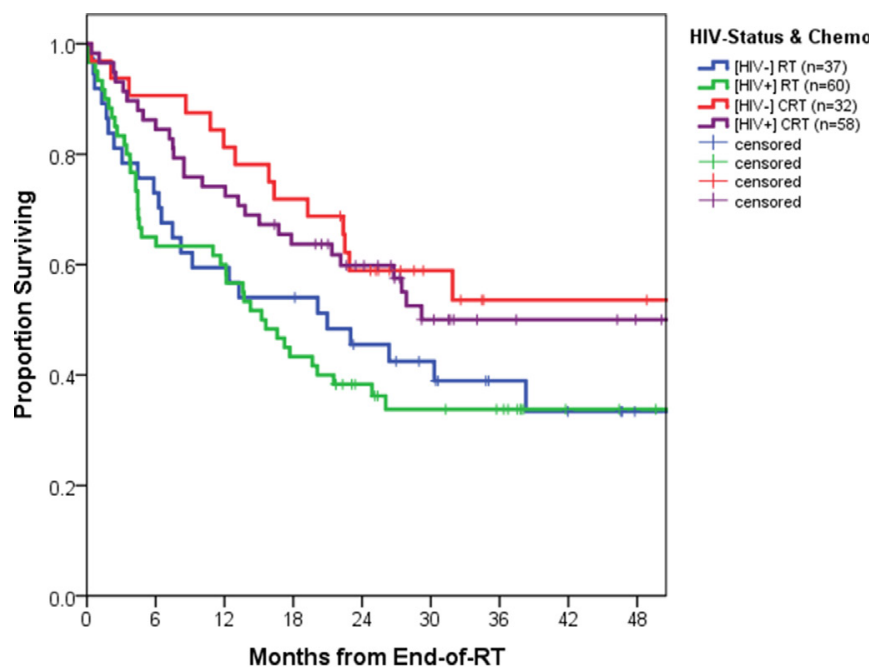

\begin{tabular}{|l|l|l|l|l|l|l|l|l|l|}
\hline $\begin{array}{l}\text { HIV-positive, } \\
\text { chemoradiation }\end{array}$ & 58 & 50 & 43 & 36 & 29 & 19 & 14 & 13 & 11 \\
\hline $\begin{array}{l}\text { HIV-positive, } \\
\text { radiation alone }\end{array}$ & 60 & 39 & 36 & 26 & 18 & 14 & 12 & 5 & 4 \\
\hline $\begin{array}{l}\text { HIV-negative, } \\
\text { chemoradiation }\end{array}$ & 32 & 29 & 26 & 23 & 18 & 11 & 7 & 7 & 7 \\
\hline $\begin{array}{l}\text { HIV-negative, } \\
\text { radiation alone }\end{array}$ & 37 & 27 & 22 & 20 & 15 & 12 & 7 & 5 & 2 \\
\hline
\end{tabular}

Figure 3 Survival outcomes by human immunodeficiency virus (HIV) status and treatment group among all International Federation of Gynecology and Obstetrics (FIGO) 2009 stage IIIB cervical cancer patients in Botswana: HIV positive, chemoradiation therapy (CRT) $(n=58)$; HIV positive, radiation therapy (RT) alone ( $n=60)$; HIV negative, CRT $(n=32)$; HIV negative, $R T$ alone $(n=37)$. HIV positive patients similarly benefited from concurrent CRT. 
Table 2 Factors associated with overall survival in FIGO 2009 stage IIIB cervical cancer in Botswana: univariate and multivariable analyses $(n=187)$

\begin{tabular}{|c|c|c|c|c|c|}
\hline Factor & $\mathbf{N}$ & $\begin{array}{l}\text { Overall survival, UVA } \\
\text { (HR (95\% CI)) }\end{array}$ & $P$ value & $\begin{array}{l}\text { Overall survival, MVA } \\
\text { (HR }(95 \% \mathrm{Cl}))\end{array}$ & $P$ value \\
\hline Age ( $\geq 50$ years) & 89 & 1.04 (0.71 to 1.53$)$ & 0.85 & $1.23(0.72$ to 2.07$)$ & 0.449 \\
\hline HIV status (seropositive) & 118 & 1.14 (0.76 to 1.70$)$ & 0.53 & 1.50 (0.88 to 2.57$)$ & 0.138 \\
\hline Weight $(\mathrm{kg})(\geq 60)^{\star}$ & 81 & $0.69(0.45$ to 1.06$)$ & 0.09 & & \\
\hline Body mass index $\left(\mathrm{kg} / \mathrm{m}^{2}\right)(\leq 20)^{*}$ & 42 & 1.13 (0.70 to 1.83$)$ & 0.61 & & \\
\hline Tumor histology (SCC vs non-SCC) & 165 & 0.99 (0.55 to 1.82$)$ & 0.99 & & \\
\hline History of tuberculosis (yes) & 17 & $0.84(0.41$ to 1.73$)$ & 0.63 & & \\
\hline CD4 count $(<400)^{\star}$ & 62 & 1.52 (0.91 to 2.55$)$ & 0.11 & & \\
\hline Viral load $(\geq 400)^{\star}$ & 11 & 1.24 (0.56 to 2.74$)$ & 0.60 & & \\
\hline Hemoglobin $(\mathrm{g} / \mathrm{dL})(<12)^{\star}$ & 139 & 1.35 (0.79 to 2.31$)$ & 0.28 & $1.10(0.61$ to 1.96$)$ & 0.759 \\
\hline Creatinine $(\mu \mathrm{mol} / \mathrm{L})(>90)^{*}$ & 31 & 1.45 (0.89 to 2.38$)$ & 0.14 & & \\
\hline KPS $(40-80 \text { vs } 90-100)^{*}$ & 54 & 1.33 (0.88 to 2.01$)$ & 0.18 & $1.27(0.81$ to 1.96$)$ & 0.294 \\
\hline ART (yes) & 110 & $1.41(0.51$ to 3.87$)$ & 0.51 & & \\
\hline \multicolumn{6}{|l|}{ Treatment } \\
\hline Total RT dose, EQD2 ( $\geq 80$ Gy) & 65 & 0.52 (0.34 to 0.82$)$ & 0.04 & 0.57 (0.35 to 0.92$)$ & 0.023 \\
\hline 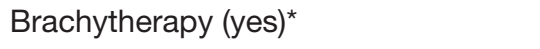 & 120 & $0.42(0.28$ to 0.62$)$ & $<0.01$ & & \\
\hline CRT (yes) & 90 & $0.57(0.38$ to 0.85$)$ & 0.01 & 0.63 (0.39 to 0.99$)$ & 0.045 \\
\hline Treatment response $\left(\right.$ complete) ${ }^{*} \dagger$ & 80 & 0.45 (0.29 to 0.70$)$ & $<0.01$ & & \\
\hline Treatment year (2013-15 vs 2016-18) & 73 & 0.85 (0.57 to 1.27$)$ & 0.43 & & \\
\hline $\mathrm{TTT}(>3 \text { months })^{*} \ddagger$ & 90 & 1.16 (0.73 to 1.84$)$ & 0.54 & & \\
\hline RT course length $(<7 \text { weeks })^{*}$ & 106 & 0.91 (0.62 to 1.35$)$ & 0.642 & & \\
\hline
\end{tabular}

${ }^{*}$ Data are incomplete due to missing individual patient data.

†Treatment response is defined as clinically apparent tumor regression on examination.

$\ddagger T T$ is defined as time from pathological diagnosis to initiation of treatment.

ART, antiretroviral therapy; CRT, chemoradiation therapy; EQD2, radiobiological equivalent dose; FIGO, International Federation of

Gynecology and Obstetrics; HIV, human immunodeficiency virus; KPS, Karnofsky Performance Score; MVA, multivariable analysis; RT,

radiation therapy; SCC, squamous cell carcinoma; UVA, univariate multivariable analysis.

characteristics between the two groups were comparable for the following factors: weight, body mass index, and baseline Karnofsky Performance Status score.

\section{Treatment Characteristics}

Time-to-treatment was defined as the time from pathological diagnosis to commencement of treatment. Time-to-treatment was more than 3 months for $58(60 \%)$ of 96 women living with HIV and for $32(68 \%)$ of 47 women without HIV. Following initial external beam radiation therapy (median dose 50 Gy, IQR 45-50.4 Gy), $120(64 \%)$ of 187 patients received high dose rate brachytherapy (median 22.5 Gy in 3-4 fractions, IQR 21-27.6 Gy); 58 (31\%) of 187 patients underwent pelvic external beam radiation therapy boost (median 10 Gy in five fractions, IQR 5.4-12.4 Gy). Total radiation received by patients was $\geq 80$ Gy to point A in 65 (35\%) of 187 patients. The median total radiation dose among the cohort was 68 Gy (IQR 55-74). Patients who did not receive a total radiation dose $\geq 80$ Gy were more likely to have a low body weight $(p=0.04)$ and elevated creatinine $(p=0.05)$ although performance status was found to be statistically significant among the two groups (Online Supplemental Appendix A).

About half of the patients $(58 / 118,48 \%)$ were treated with concurrent cisplatin based chemoradiation. The most common dose was $35-40 \mathrm{mg} / \mathrm{m}^{2}$ over a median of 2 cycles (IQR $1-6$ cycles). Elevated creatinine $(p<0.01)$ and low hemoglobin $(p<0.01)$ were significantly associated with withholding chemotherapy, while performance status was not $(p=0.31)$ (Online Supplemental Appendix B).

\section{Overall Survival}

Median overall survival for the study population was 23 months (95\% Cl 16.5 to 29.5 months). The 1, 2, and 3 year overall survival rates were $68 \%, 50 \%$, and $43 \%$, respectively. Receipt of concurrent chemotherapy was associated with a significant improvement in 2 year overall survival rates among the entire cohort: $59.4 \pm 5.2 \%$ with chemoradiation versus $41.0 \pm 5.0 \%$ for radiation alone $(p<0.01)$ (Figure 1). Median survival was 57.3 months $(95 \% \mathrm{Cl} \mathrm{N} / \mathrm{A})$ versus 16.6 months ( $95 \% \mathrm{Cl} 10.6$ to 22.6 months), respectively.

In terms of HIV status, median overall survival was 21.5 months (95\% Cl 12.9 to 30.1 months) for women living with HIV versus 30.3 months (95\% Cl 16.6 to 44.0 months) for women without HIV $(p=0.53)$ (Figure 2). Women living with HIV similarly benefited from concurrent chemoradiation. The 2 year overall survival was $59.8 \pm 6.5 \%$ in the chemoradiation group of women living with HIV versus $38.3 \pm 6.3 \%$ in the radiation alone group (log rank, $p=0.02$ ) (Figure 3 ) while median survival was 57.3 months $(95 \% \mathrm{Cl} 16.1$ to 
Table 3 Stratified multivariable analysis for patients who received a total radiation dose $\geq 80$ Gy $(n=65)$

\begin{tabular}{lll}
\hline Factor & $\begin{array}{l}\text { Overall survival, } \\
\text { MVA (HR (95\% Cl)) }\end{array}$ & P value \\
\hline Age ( $\geq 50$ years) & $1.07(0.48$ to 2.41$)$ & 0.86 \\
HIV status (positive) & $1.22(0.51$ to 2.91$)$ & 0.66 \\
CRT (yes) & $1.13(0.49$ to 2.62$)$ & 0.77 \\
\hline
\end{tabular}

CRT, chemoradiation; HIV, human immunodeficiency virus; MVA, multivariable analysis.

98.6 months) versus 15.2 months ( $95 \% \mathrm{Cl} 10.6$ to 19.8 months), respectively. Among women without HIV, 2 year overall survival was $58.9 \pm 8.8 \%$ in the chemoradiation group versus $45.5 \pm 8.2 \%$ in the radiation alone group (log rank, $p=0.086$ ). Median survival of the latter group was 21.0 months ( $95 \%$ Cl 5.1 to 36.8 months) and did not differ from women with HIV receiving radiation alone (log rank, $\mathrm{p}=0.65)$.

Among patients who received adequate radiation (defined as a total radiation dose $\geq 80$ Gy to point A), survival outcomes were similar with or without concurrent chemotherapy: 2 year overall survival was $61.7 \pm 7.6 \%$ months in the chemoradiation arm versus $57.1 \pm 7.3 \%$ in the radiation alone arm $(p=0.77)$ (Online Supplemental Appendix C). However, in patients who received inadequate radiation (total radiation dose $<80$ Gy to point A), 2 year overall survival was significantly improved with the addition of chemotherapy: $51.9 \pm 14.3 \%$ in the chemoradiation group versus $34.3 \pm 5.5 \%$ with radiation alone $(p<0.01)$ (Online Supplemental Appendix D).

With univariate Cox regression analysis, various treatment factors were associated with 2 year overall survival: radiation total dose $\geq 80$ Gy (HR $0.52,95 \% \mathrm{Cl} 0.34$ to 0.82 ), receipt of brachytherapy (HR $0.42,95 \% \mathrm{Cl} 0.28$ to 0.62 ), and a complete treatment response ( $\mathrm{HR}$ $0.45,95 \% \mathrm{Cl} 0.29$ to 0.70 ) (Tables 2-4). Consistent with KaplanMeier survival analysis, HIV status was not found to be related to 2 year overall survival (HR 1.14, $\mathrm{p}=0.53$ ).

For multivariable analysis, 2 year overall survival was found to be associated with total radiation dose $\geq 80$ Gy $(\mathrm{p}=0.023)$ and receipt of chemotherapy ( $p=0.045$ ) (Tables $2-4)$. Total radiation dose was found to modify the effect of chemotherapy on overall survival. Among patients whose total radiation dose received was $\geq 80$ Gy $(n=65)$, the rate of 2 year overall survival was not significantly

Table 4 Stratified multivariable analysis for patients who received a total radiation dose $<80$ Gy $(n=111)^{\star}$

\begin{tabular}{lll}
\hline Factor & $\begin{array}{l}\text { Overall survival, } \\
\text { MVA (HR (95\% Cl)) }\end{array}$ & P value \\
\hline Age ( $\geq 50$ years) & $1.05(0.54$ to 2.04$)$ & 0.88 \\
HIV status (seropositive) & $1.42(0.74$ to 2.73$)$ & 0.29 \\
KPS (40-80) & $1.09(0.64$ to 1.86$)$ & 0.76 \\
Hemoglobin $(<12 \mathrm{~g} / \mathrm{dL})$ & $0.85(0.44$ to 1.64$)$ & 0.62 \\
CRT (yes) & $0.45(0.25$ to 0.82$)$ & 0.01 \\
\hline
\end{tabular}

${ }^{*}$ Cases with missing data excluded.

CRT, chemoradiation; HIV, human immunodeficiency virus; KPS, Karnofsky Performance Score; MVA, multivariable analysis.; higher with receipt of chemotherapy after adjustment for covariates (adjusted HR 1.07; 95\% Cl 0.40 to 2.89). Alternatively, among those who received a total radiation dose $<80 \mathrm{~Gy}(\mathrm{n}=122)$, adjusted overall survival rates were significantly higher among those patients in the chemoradiation group (adjusted HR $0.45 ; 95 \% \mathrm{Cl}$ 0.25 to 0.82$)$.

\section{DISCUSSION}

\section{Summary of Main Results}

In this prospective cohort study of patients in Botswana with clinically staged IIIB cervical cancer, chemoradiation was associated with improved overall survival for all patients regardless of HIV status. The subgroup of women living with HIV similarly benefitted from the addition of chemotherapy as women without HIV. Additionally, total radiation dose $\geq 80$ Gy was found to directly contribute to improved overall survival. Our data provide evidence for the benefit of both concurrent chemotherapy and radiation (including external beam radiation therapy and brachytherapy) for stage IIIB disease in a resource limited setting, and further emphasizes that HIV status should not preclude aggressive definitive management.

\section{Results in the Context of Published Literature}

Previous cervical cancer data suggest that survival benefit from concurrent chemotherapy is stage dependent, ${ }^{13}$ but for stage IIIB, there have been inconsistent findings. ${ }^{8-15} 17-23$ However, many of these prior studies, including a meta-analysis ${ }^{12}$ and a randomized trial of patients from Botswana, ${ }^{13}$ have been limited by various factors, including inconsistent chemotherapy regimens, radiation dose, treatment time, use of brachytherapy, and small sample sizes. ${ }^{9-13}$ Our study, which found an $18 \%$ increase in 2 year overall survival with chemoradiation for stage IIIB patients, is concordant with findings from the appropriately powered, randomized trial by Shrivastava et al, ${ }^{15}$ which found an $8 \%$ increase in 5 year overall survival with chemoradiation in patients with stage IIIB cervical disease.

Furthermore, our study addresses the paucity of data regarding the significance of chemoradiation versus radiation in women living with HIV with stage IIIB disease. Although Shrivastava et al ${ }^{15}$ found chemoradiation compared with radiation alone improved both disease free survival and overall survival, the study excluded women who were co-infected with HIV at diagnosis. Our data confirm the benefit of chemoradiation for all patients, regardless of HIV disease status. This finding remains consistent with other studies that have evaluated the effectiveness of treatments of patients in an antiretroviral therapy era, ${ }^{6} 2627$ thus further emphasizing the importance of appropriate cancer treatment for women living with HIV.

Our analysis found that a total radiation dose $\geq 80$ Gy was associated with increased 2 year overall survival. This is consistent with the recommended total radiation dose $>85$ Gy for locally advanced cervical cancer. ${ }^{28}$ Similarly, Shrivastava et $a{ }^{15}$ found that a point A total radiation dose $\geq 68$ Gy was associated with both disease free and overall survival. In the present analysis, the majority of patients received adequate external beam radiation therapy; however, only $64 \%$ of patients received high dose rate brachytherapy, which is necessary to achieve a total radiation dose $>85 \mathrm{~Gy}$. This is often the case in limited resource settings such as Botswana where image guided brachytherapy is not accessible. Thus it remains vital to 


\section{Original research}

understand if outcomes can be improved with higher total radiation doses.

Interestingly, the effect of chemoradiation on overall survival was not significant when analysis was limited to patients receiving a total radiation dose $\geq 80 \mathrm{~Gy}$. Given the role of cisplatin as a radiation sensitizer, ${ }^{28}{ }^{29}$ this suggests that higher radiation dose could compensate for this role. A finding such as this is an important strategy to keep in mind for low resourced areas that may not be able to provide both high quality radiation and cisplatin therapy but may have the capacity to provide one or the other.

\section{Study Limitations}

Various limitations exist among our findings. We recognize that the study was underpowered to isolate more modest effect sizes. Additionally, our study is inherently limited by the lack of nonrandomization of patients who received radiation versus chemoradiation. This introduces selection bias that may ultimately influence our findings. Furthermore, there exists uncontrollable inherent biases among the treatment groups that we were unable to control for, such as clinical, socioeconomic, and practice era. Although through both multivariable and effect modification analyses, we identified and adjusted for differences in the pre-treatment patient characteristics to better account for the variables that may impact our conclusions, due to the design of this study we cannot completely adjust for pre-treatment variables that may have placed patients in the radiation versus the chemoradiation treatment group. Furthermore, patients were clinically staged based on the FIGO 2009 staging criteria. Previously, it has been demonstrated that inclusion of both surgical pathology and imaging often results in a higher stage migration for a majority of patients who were originally clinically staged using FIG0 2009 staging criteria. The higher stage results often from findings of distant or nodal metastases that were not clinically appreciated. Furthermore, the majority of our patients living with HIV (93\%) had received antiretroviral therapy prior to starting therapy. Among the cohort, the median CD4 count was 445 cells $/ \mathrm{mL}$ and $87 \%$ had a viral load $<400$ cells $/ \mathrm{mL}$. Thus we cannot exclude the fact that HIV may ultimately impact clinical outcomes for women without well controlled HIV infection. However, our cohort did not allow for testing of this hypothesis as only $13 \%$ had not received antiretroviral therapy prior to treatment initiation. Lastly, data collected during follow-up were restricted to vital status and did not evaluate treatment tolerance, toxicities, tumor recurrence, or quality of life metrics.

\section{Implications for Practice and Future Research}

Given the high prevalence of HIV and cervical cancer co-infection in sub-Saharan Africa, it remains imperative to understand the optimal cervical cancer treatment paradigm for women with HIV, especially for those with advanced stage disease. Our results indicate that all stage IIIB cervical cancer patients, regardless of HIV status, should receive, when feasible, standard chemoradiation.

\section{CONCLUSIONS}

In summary, overall survival for stage IIIB cervical cancer in women, with or without HIV infection, was significantly improved when women were treated with chemoradiation versus radiation alone. Additionally, chemotherapy was especially vital for patients receiving inadequate dose of radiation.

\author{
Author affiliations \\ ${ }^{1}$ Radiation Oncology, University of Pennsylvania, Philadelphia, Pennsylvania, USA \\ ${ }^{2}$ Oncology, University of Botswana, Gaborone, Botswana \\ ${ }^{3}$ Radiation Oncology, University of Texas MD Anderson Cancer Center Division of \\ Radiation Oncology, Houston, Texas, USA \\ ${ }^{4}$ Radiation Oncology, The University of British Columbia, Vancouver, British \\ Columbia, Canada \\ ${ }^{5}$ Radiation Oncology, University of California San Francisco, San Francisco, \\ California, USA \\ ${ }^{6}$ The University of Texas Southwestern Medical Center, Dallas, Texas, USA \\ ${ }^{7}$ Life Gaborone Private Hospital, Gaborone, Gaborone, Botswana \\ ${ }^{8}$ Radiation Oncology, The University of Texas MD Anderson Cancer Center, Houston, \\ Texas, USA \\ ${ }^{9}$ Princess Marina Hospital, Gaborone, Gaborone, Botswana \\ ${ }^{10}$ Obstetrics and Gynecology, Beth Israel Deaconess Medical Center, Boston, \\ Massachusetts, USA \\ ${ }^{11}$ Obstetrics \& Gynaecology - Faculty of Medicine, University of Botswana, \\ Gaborone, Botswana \\ ${ }^{12}$ Microbiology, University of Pennsylvania, Philadelphia, Pennsylvania, USA \\ ${ }^{13}$ Botswana-University of Pennsylvania Partnership, Philadelphia, Pennsylvania, USA
}

Correction notice This article has been corrected since it was first published. The median follow-up time within the cohort was incorrectly reported. The correct follow-up time is 22 months ( $95 \% \mathrm{Cl} 8$ to 34 months).

Acknowledgements We thank Susan Krown for reviewing the manuscript prior to submission.

Contributors SG: study design, data analysis, interpretation, literature search, writing, and final review of the manuscript. MSN: data analysis, figures and tables, interpretation, writing, and final review of the manuscript. MB: data collection and data cleaning. KEL: literature search, writing, and review. SS: literature search, writing, and review. MB-N, SC, DB, GJM, TR, TM, RL, DR-M, ESR: data interpretation, editing, and final review of the manuscript. NMZ: study design, data analysis, interpretation, and final review of the manuscript.

Funding The Mentored Patient Oriented Career Research Development Award (1-K08CA230170-01A1), Department of Radiation Oncology, University of Pennsylvania, and Sub-Saharan African Collaborative HIV and Cancer Consortia-U54 (1U54 CA190158-01).

Competing interests None declared.

Patient consent for publication Not required.

Ethics approval The institutional review board of the University of Pennsylvania approved the study (IRB 820159).

Provenance and peer review Not commissioned; externally peer reviewed.

Data availability statement Data are available upon reasonable request. The data that support the findings of this study are available on request from the corresponding author, SG. The data are not publicly available due to restrictions (eg, the data contain information that could compromise the privacy of research participants).

Supplemental material This content has been supplied by the author(s). It has not been vetted by BMJ Publishing Group Limited (BMJ) and may not have been peer-reviewed. Any opinions or recommendations discussed are solely those of the author(s) and are not endorsed by BMJ. BMJ disclaims all liability and responsibility arising from any reliance placed on the content. Where the content includes any translated material, BMJ does not warrant the accuracy and reliability of the translations (including but not limited to local regulations, clinical guidelines, terminology, drug names and drug dosages), and is not responsible for any error and/or omissions arising from translation and adaptation or otherwise.

\section{REFERENCES}

1 Sung H, Ferlay J, Siegel RL, et al. Global cancer statistics 2020: GLOBOCAN estimates of incidence and mortality worldwide for 36 cancers in 185 countries. CA Cancer J Clin 2021;71:209-49. 
2 Ghebre RG, Grover S, Xu MJ, et al. Cervical cancer control in HIV-infected women: past, present and future. Gynecol Oncol Rep 2017;21:101-8.

3 Petignat P, Roy M. Diagnosis and management of cervical cancer. BMJ 2007;335:765-8.

4 Moscicki A-B, Ellenberg JH, Farhat S, et al. Persistence of human papillomavirus infection in HIV-infected and -uninfected adolescent girls: risk factors and differences, by phylogenetic type. $J$ Infect Dis 2004;190:37-45.

5 Yimer NB, Mohammed MA, Solomon K, et al. Cervical cancer screening uptake in sub-Saharan Africa: a systematic review and meta-analysis. Public Health 2021;195:105-11.

6 Grover S, Bvochora-Nsingo M, Yeager A, et al. Impact of human immunodeficiency virus infection on survival and acute toxicities from chemoradiation therapy for cervical cancer patients in a limitedresource setting. Int J Radiat Oncol Biol Phys 2018;101:201-10.

7 UNAIDS. Country Factsheets: Botswana 2018, 2020. https://www. unaids.org/en/regionscountries/countries/botswana

8 Keys HM, Bundy BN, Stehman FB, et al. Cisplatin, radiation, and adjuvant hysterectomy compared with radiation and adjuvant hysterectomy for bulky stage lb cervical carcinoma. N Engl J Med 1999;340:1154-61.

9 Morris M, Eifel PJ, Lu J, et al. Pelvic radiation with concurrent chemotherapy compared with pelvic and para-aortic radiation for high-risk cervical cancer. N Engl J Med 1999;340:1137-43.

10 Peters WA, Liu PY, Barrett RJ, et al. Concurrent chemotherapy and pelvic radiation therapy compared with pelvic radiation therapy alone as adjuvant therapy after radical surgery in high-risk earlystage cancer of the cervix. J Clin Oncol 2000;18:1606-13.

11 Rose PG, Bundy BN, Watkins EB, et al. Concurrent cisplatin-based radiotherapy and chemotherapy for locally advanced cervical cancer. N Engl J Med 1999;340:1144-53.

12 Whitney CW, Sause W, Bundy BN, et al. Randomized comparison of fluorouracil plus cisplatin versus hydroxyurea as an adjunct to radiation therapy in stage IIB-IVA carcinoma of the cervix with negative para-aortic lymph nodes: a Gynecologic Oncology Group and Southwest Oncology Group study. J Clin Oncol 1999;17:1339-48.

13 Chemoradiotherapy for Cervical Cancer Meta-Analysis Collaboration. Reducing uncertainties about the effects of chemoradiotherapy for cervical cancer: a systematic review and meta-analysis of individual patient data from 18 randomized trials. $J$ Clin Oncol 2008;26:5802-12.

14 Zuliani AC, Esteves SCB, Teixeira LC, et al. Concomitant cisplatin plus radiotherapy and high-dose-rate brachytherapy versus radiotherapy alone for stage IIIB epidermoid cervical cancer: a randomized controlled trial. J Clin Oncol 2014;32:542-7.

15 Shrivastava S, Mahantshetty U, Engineer R, et al. Cisplatin chemoradiotherapy vs radiotherapy in FIGO stage IIIB squamous cell carcinoma of the uterine cervix: a randomized clinical trial. JAMA Oncol 2018;4:506-13.

16 Green J, Kirwan J, Tierney J, et al. Concomitant chemotherapy and radiation therapy for cancer of the uterine cervix. Cochrane Database Syst Rev 2005:Cd002225.

17 Price AJ, Ndom P, Atenguena E, et al. Cancer care challenges in developing countries. Cancer 2012;118:3627-35.

18 Li M, Hu M, Wang Y, et al. Adjuvant chemoradiotherapy versus radiotherapy in cervical cancer patients with intermediate-risk factors: a systematic review and meta-analysis. Eur J Obstet Gynecol Reprod Biol 2019;238:1-6.

19 UNAIDS. Cervical cancer and HIV - two diseases, one response, 2018. https://www.unaids.org/en/resources/presscentre/ featurestories/2018/october/cervical-cancer-and-hiv

20 Grover S, Chiyapo SP, Puri P, et al. Multidisciplinary gynecologic oncology clinic in Botswana: a model for multidisciplinary oncology care in low- and middle-income settings. J Glob Oncol 2017;3:666-70.

21 Schag CC, Heinrich RL, Ganz PA. Karnofsky performance status revisited: reliability, validity, and guidelines. J Clin Oncol 1984;2:187-93.

22 American Brachytherapy Society. Brachytherapy guidelines and consensus statements. Reston, VA: American Brachytherapy Society, 2016.

23 Abu-Rustum N. NCCN guidelines version 4.2019 cervical cancer. National Comprehensive Cancer Network, 2019. https://www2.trikobe.org/nccn/guideline/gynecological/english/cervical.pdf

24 World Health Organization. Interim who clinical staging of HIVIAIDS and HIVIAIDS case definitions for surveillance: African region, 2005. https://apps.who.int/iris/bitstream/handle/10665/69058/WHO_HIV_ 2005.02.pdf? sequence $=1$ \&isAllowed $=y$

25 Makhema J, Wirth KE, Pretorius Holme M, et al. Universal testing, expanded treatment, and incidence of HIV infection in Botswana. $N$ Engl J Med 2019:381:230-42.

26 Gizaw M, Addissie A, Getachew S, et al. Cervical cancer patients presentation and survival in the only oncology referral hospital, Ethiopia: a retrospective cohort study. Infect Agent Cancer 2017;12:61.

27 Simonds $\mathrm{HM}$, Botha $\mathrm{MH}$, Neugut Al, et al. Five-year overall survival following chemoradiation among HIV-positive and HIV-negative patients with locally advanced cervical carcinoma in a South African cohort. Gynecol Oncol 2018:151:215-20.

28 Dimopoulos JCA, Pötter R, Lang S, et al. Dose-effect relationship for local control of cervical cancer by magnetic resonance imageguided brachytherapy. Radiother Oncol 2009;93:311-5.

29 Boeckman HJ, Trego KS, Turchi JJ. Cisplatin sensitizes cancer cells to ionizing radiation via inhibition of nonhomologous end joining. Molecular cancer research: MCR, 2005: 3. 277-85. 